\title{
CONF-9504/2--22
}

Note: This is a preprint of paper being submitted for publication. Contents of this paper should not be quoted nor referred to without permission of the author(s).

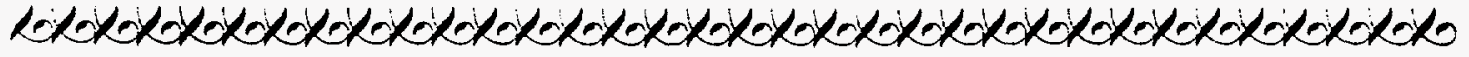

Su6mitted to Symposium Q: Film Synthesis and Growth Using Energetic Beams

Materials Research Society Meeting

San Francisco Marriott, San Francisco, CA

April 17-21, 1995

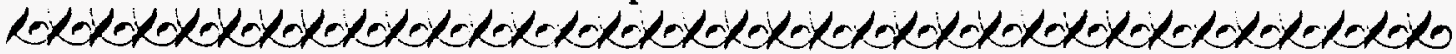

\section{COLLISIONAL EFFECTS OF BACKGROUND GASES ON PULSED LASER DEPOSITION PLASMA BEAMS}

DAVID B. GEOHEGAN* AND ALEX A. PURETZKY**

*Oak Ridge National Laboratory, P.O. Box 2008. Oak Ridge, TN 37831-6056.

**Institute of Spectroscopy, Russian Academy of Sciences. Troitsk, Russia.

April 1995

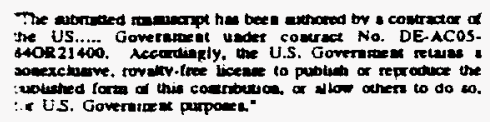

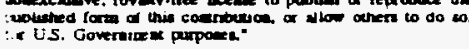

Prepared by

Solid State Division

Oak Ridge National Laboratory

P.O. Box 2008

Oak Ridge, Tennessee 37831-6056

managed by MARTIN MARIETTA ENERGY SYSTEMS, INC.

for the

U.S. DEPARTMENT OF ENERGY

under contract DE-AC05-84OR21400

12

DISTRIBUTION OF THIS DOCUMENT IS UNLIMITED 


\section{DISCLAIMER}

This report was prepared as an account of work sponsored by an agency of the United States. Government. Neither the United States Government nor any agency thereof, nor any of their employees, make any warranty, express or implied, or assumes any legal liability or responsibility for the accuracy, completeness, or usefulness of any information, apparatus, product, or process disclosed, or represents that its use would not infringe privately owned rights. Reference herein to any specific commercial product, process, or service by trade name, trademark, manufacturer, or otherwise does not necessarily constitute or imply its endorsement, recommendation, or favoring by the United States Government or any agency thereof. The views and opinions of authors expressed herein do not necessarily state or reflect those of the United States Government or any agency thereof. 


\section{DISCLAIMER}

Portions of this document may be illegible in electronic image products. Images are produced from the best available original document. 


\title{
COLLISIONAL EFFECTS OF BACKGROUND GASES ON PULSED LASER DEPOSITION PLASMA BEAMS
}

\author{
DAVID B. GEOHEGAN* AND ALEX A. PURETZKY** \\ *Oak Ridge National Laboratory, P.O. Box 2008, Oak Ridge, TN 37831-6056. \\ **Institute of Spectroscopy, Russian Academy of Sciences, Troitsk. Russia.
}

\begin{abstract}
The penetration of energetic pulsed ablation plumes through ambient gases is experimentally characterized to investigate a general phenomenon believed to be important to film growth by pulsed laser deposition (PLD). Under typical PLD conditions involving background gases, the ion flux in the ablation plume is observed to split into distinct fast and slow components over a limited range of distances. 1.2 The tast component is transmitted with near-initial velocities and high kinetic energies, potentially damaging to growing films at these distances. Formation of the second. significantly-slowed component correlates with the bright contact front ${ }^{3}$ formation observed 1,4 in fast ICCD imaging studies. This general effect is explored in detail for the case of yttrium ablation into argon. a single-element target into an inert gas. 5 Time-resolved optical absorption spectroscopy and optical emission spectroscopy are employed to simultaneously view the populations of both excited and ground states of $\mathrm{Y}$ and $\mathrm{Y}^{+}$for comparison with quantitative intensified-CCD photography of the visible plume luminescence and ion flux measurements made with fast ion probes during this phenomenon. These measurements confirm that. in addition to the bright significantly-slowed front which has been described by shock or drag propagation models ${ }^{1}$, a fast-component of target material is transmitted to extended distances for some ambient pressures with near-initial velocities.
\end{abstract}

\section{INTRODUCTION}

The ability of energetic ablation plasma plumes or 'beams' to penetrate low-pressure background gases during PLD is a key processing advantage. However, the plume/backgroundgas interaction is a mixture of gas-dynamic and thermal effects which result in nontrivial variations of key processing parameters with distance, namely: kinetic energy, density, and temperature. Reported here are combined diagnostic measurements of silicon and yttrium ablation plume penetration through inert background gases during a key transitional regime in which the ion flux is split into distinct fast and slowed components. This apparently general phenomenon occurs over a limited range of distances at ambient pressures, including those sometimes used for PLD (as reported for YBCO ablation into $\mathrm{O}_{2}$ ) 1,2,6,7 This "plume-splitting" is significant because a 'fast' component of ions can arrive at the ion probe (or substrate) with little or no delay compared to propagation in vacuum (e.g., $\mathrm{Y}^{+}$kinetic energies in this study were up to $250 \mathrm{eV}$, and $\mathrm{Si}^{+}$up to $215 \mathrm{eV}$ ). Kools recently employed a Monte Carlo simulation involving elastic collisions to prove this possibility. ${ }^{8}$ However, at longer distances this 'fast' component is completely attenuated, and a single, slowed distribution of ions is observed. This 'fast' component is easily overlooked in imaging studies because enhanced plume luminescence occurs in the slowed distribution.

However, the transmitted flux is readily observed with fast ion probes which provide convenient measurements of the magnitude and time-of-flight of the ion current (flux) in phama plumes propagating through background gases. 1,2,5-7,9 Figure 1 serves to review the ion probe measurements and illustrate the splitting effect.

Figure 1(a) shows the ion flux arriving at $d=5 \mathrm{~cm}$ along the normal to a silicon target following $2.8 \mathrm{~J} / \mathrm{cm}^{2} \mathrm{KrF}$-laser irradiation in vacuum and various helium ambient pressures. As in the case of YBCO penetrating through $\mathrm{O}_{2}, 1,2,6,7$ the ion flux in these $\mathrm{Si} / \mathrm{He}$ and $\mathrm{Si} / \mathrm{Ar}$ studies was attenuated exponentially with background pressure and/or distance in general agreement with the simple scattering model (effective cross sections in both cases $\sim 1 \times 10^{-16} \mathrm{~cm}^{2}$ ) utilized for YBCO. $1,2,6,7$

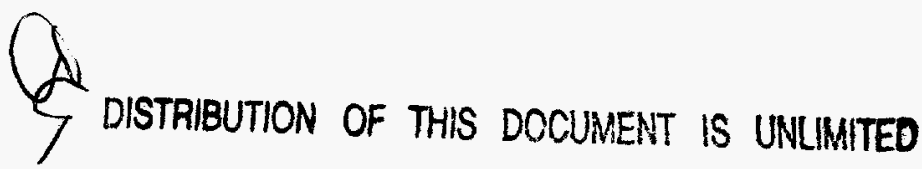



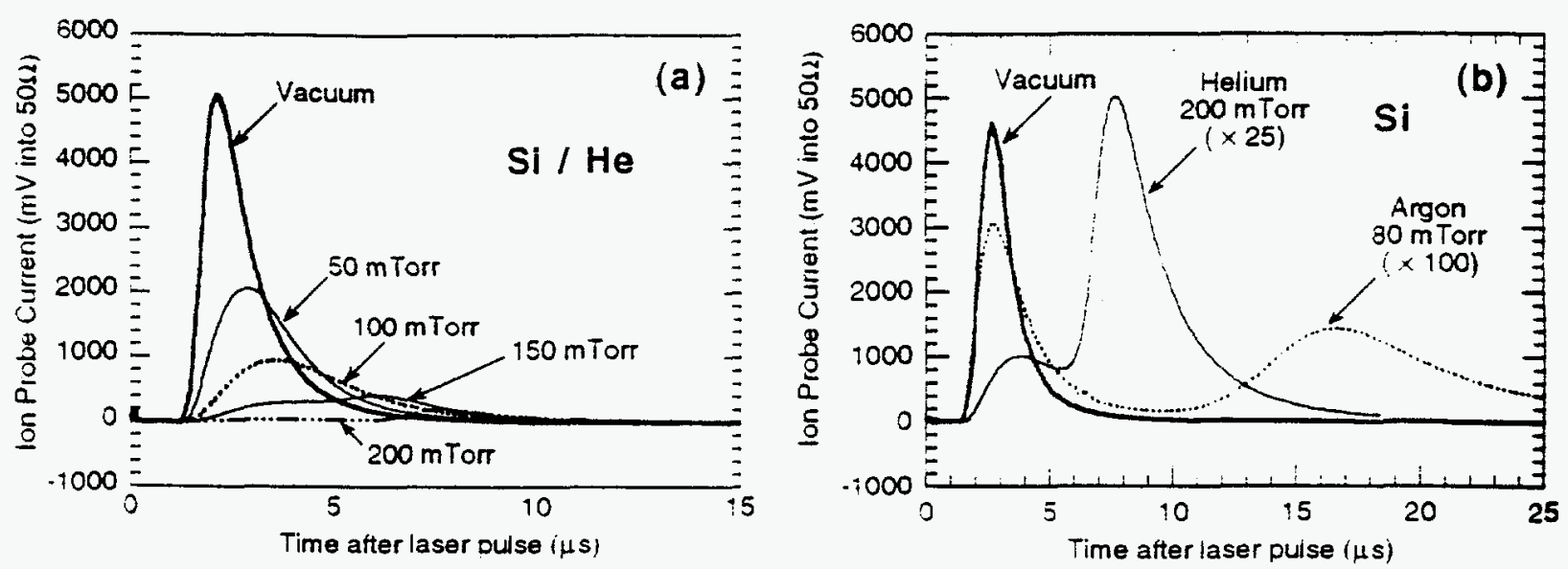

Figure 1: Ion probe current wavetorms measured $\mathrm{d}=5 \mathrm{~cm}$ along the normal from a silicon target following 2.8 $\mathrm{J} / \mathrm{cm}^{2} \mathrm{KrF}$-laser irradiation in vacuum and background helium and argon: (a) Slowing and attenuation vs. helium ambient pressure (unscaled), (b) Comparison of tast and slow ion tlux arrival at $d=5 \mathrm{~cm}$ through helium (200 $\mathrm{m}$ Torr) and argon ( $80 \mathrm{mTorr}$ ) with that in vacuum. In addition to the slowed material. a fast component of ions anrives in both cases with little or no delay comnared to the propagation in vacuum.

At long distances and long time delays, ion probe and fast imaging measurements respectively record a decelerating, stable shock-structure which propagates in accordance with drag or shock models. 6.7.9 However, for some pressure/distance combinations, two distinct ion flux distributions are resolvable as shown in Figure 1(b).

Figure 1(b) shows scaled ion tluxes measured at $\mathrm{d}=5 \mathrm{~cm}$ following laser ablation of silicon in helium (200 mTorr) and argon ( $80 \mathrm{mTorr}$, dashed curve). Despite the high background pressures, a 'fast' component of ion flux arrives at the detector position at $d=5 \mathrm{~cm}$ with little or no apparent slowing. A 'slow' component of material arrives much later, in coincidence with the arrival of the bright shock structure (as will be shown for yttrium into argon, below).

Variations of the shane of the 'fist' component with hackground gas. distance. and pressure hold clues to the tundamentals of the scattering processes at play. These will be presented elsewhere. as will the various computer models and simulations which have been undertaken. In this paper, it is necessary to prove that the 'fast' component contains fast plume ions (and not, for example. background gas ions which have been swept-up. or 'snowplowed' in front of the target material). In addition. cluantitative imagng will be introduced in support of this hypothesis.

\section{EXPERIMENTAL RESULTS}

In this paper, time- and spatially-resolved optical absorption and emission spectroscopy are applied to determine the composition of the 'fast' and 'slow' propagating plume components for single-component target ablation (yttrium) into an inert gas (argon). These measurements are correlated with quantitative imaging and ion probe measurements. Although the splitting effect appears quite general, the yttrium/argon system was chosen because optical absorption spectroscopy of both $\mathrm{Y}$ and $\mathrm{Y}^{+}$was simultaneously possible ${ }^{10}$ and because argon is chemically inert.

The experimental apparatus has been described previously. 47.10 A cylindrical lens $\left(f_{\mathrm{L}}=500\right.$ $\mathrm{mm}$ ) focused the apertured 248-nm beam from a Questek $2960 \mathrm{KrF}$-excimer laser ( $25 \mathrm{~ns}$ FWHM pulse width) to a horizontal line $(2.0 \mathrm{~cm} \times 0.075 \mathrm{~cm})$ on the face of a sanded yttrium $(99.99 \%)$ pellet at an incidence angle of $30^{\circ}$. For optical absorption spectroscopy, a pulsed (1.5 $\mu \mathrm{s}$ FWHM) Xe lamp beam (width $0.5 \mathrm{~mm}$ ) was passed parallel to the target surtace and just above a wire ion probe tip (floating bias $-70 \mathrm{~V}$ with respect to its shield). The expansion of the ablated yttrium formed a vertical fan which expanded little along the horizontal lamp beam axis (toward the camera 

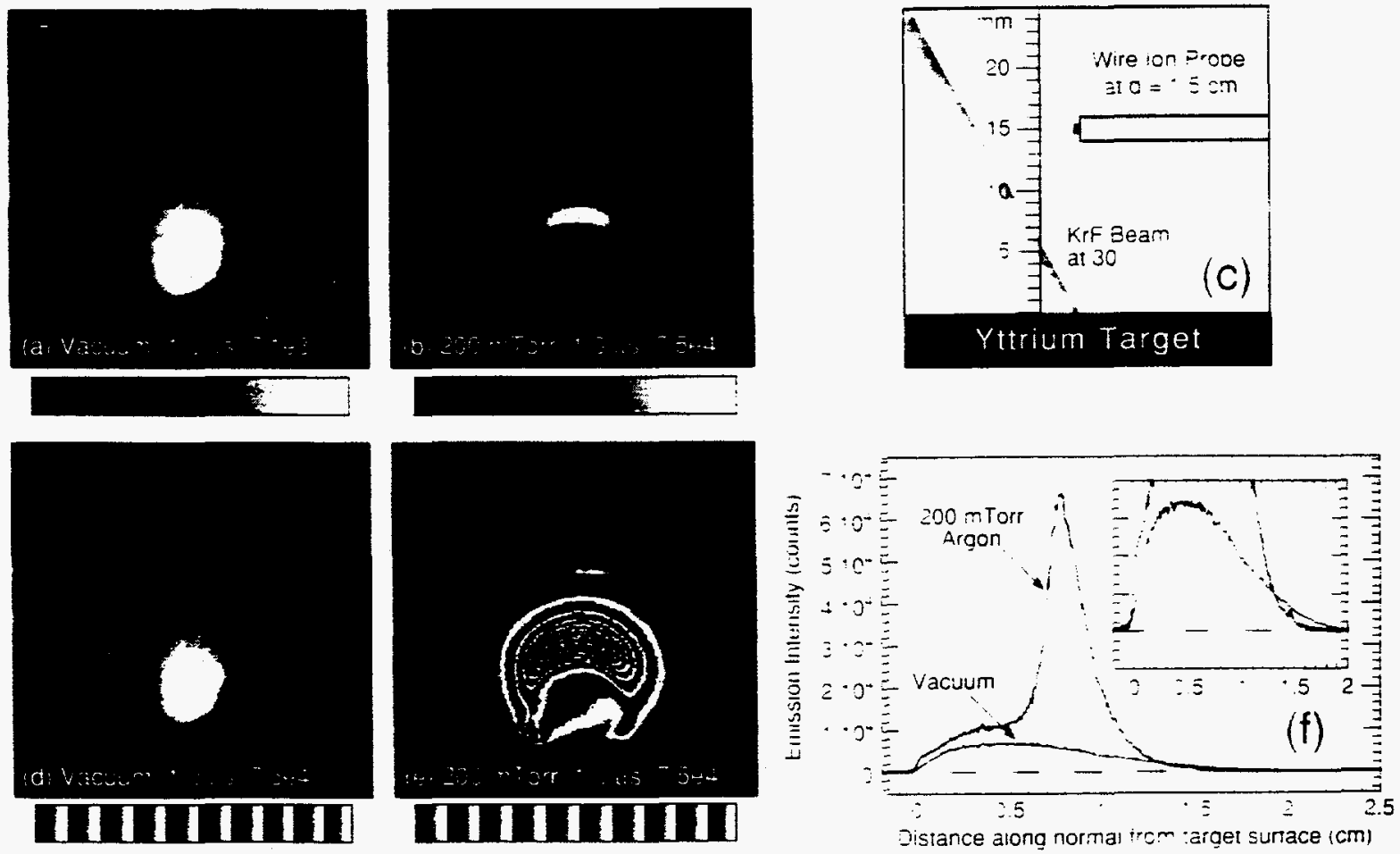

Figure 2: Gated ICCD photographs of the total visible optical plasma emission during $\lambda t=1.00-1.05 \mu \mathrm{s}$ following $0.8 \mathrm{~J} / \mathrm{cm}^{2} \mathrm{KrF}$-laser irradiation of yttrium metal into (a) $1 \times 10^{-6}$ Torr and (b) $200 \mathrm{mTorr}$ argon. The peak of the grayscale palette is normalized to 7100 and 75000 counts, respectively. (c) Schematic indicating the side-on view of the yttrium target, $\mathrm{mm}$-scale, and wire-ion probe position at $\mathrm{d}=1.5 \mathrm{~cm}$. (d), (e) The same photographs are replotted with a 10-grayscale palette and equal normalization to 75000 counts for direct comparison. A line-profile of the emission intensity from the irradiated spot along the target normal (t) shows the correct relative scaling between the vacuum and background images. The inset in ( $\mathrm{f}$ ) more clearly shows the same data replotted on a ()-8000 count scale 6 illustrate the smaul. but resolvable emission in 200 in $\Gamma$ orr argon out to and heyond $1.5 \mathrm{~cm}$.

or spectrometer), so the absorption path length remained at approximately $2 \mathrm{~cm}$ for the two distances investigated here $(\mathrm{d}=1.5,2.5 \mathrm{~cm})$. Optical detection utilized a 1.33 -meter spectrometer McPherson $209.18(1) \mathrm{g} / \mathrm{mm}$ holographic grating) outtitted with an intensified. (sated diode array Princeton Instruments IRY-7()0RB. 5-ns resolution) and photomultiplier cune (Hamamatsu R955). Fast unfiltered imaging was pertormed with a gated, (ICCD), lens-coupied camera system (Princeton Instruments) with variable gain. 2(0)-820 nm response. and variable gating above 5-ns.

Typical gated images of the visible yttrium-plume luminescence at $\Delta t=1.0 \mu$ s in vacuum and $200 \mathrm{mTorr}$ argon are shown in Figure 2(a),(b). The free expansion in vacuum (Fig. 2a) shows luminescence extending to $2.0 \mathrm{~cm}$, while the luminescence in argon (Fig. 2b) appears not to reach the ion probe at $d=1.5 \mathrm{~cm}$. However, this is a resuit of the scaling of the intensity data to accommodate the bright shock structure (over $10 \times$ brighter than the peak in Fig. 2a). When normalized to the same peak intensity, and replotted in Fig. 2(d) and 2(e) with a 10-grayscale palette, the same two images reveal luminescence extending well past the ion probe to nearly the same distances as in vacuum. A line profile along the normal to the irradiated spot [Fig. 2(f)] correctly portrays the relative intensities.

The ion probe currents collected in vacuum and $200 \mathrm{mTor}$ argon at $\mathrm{d}=1.5 \mathrm{~cm}$ are shown in Fig. 3(a). At this distance and pressure, the diminishing 'fast' component of the ion flux is still an appreciable fraction of the total signal, and is temporally well-resolved from the 'slow' component. In order to investigate the composition of the plume during the splitting of the ion flux, optical absorption spectra were obtained at $\mathrm{d}=1.5 \mathrm{~cm}$ at three times (1.3 $\mu \mathrm{s}, 2.1 \mathrm{us}$. and $2.9 \mu \mathrm{s})$ corresponding to times during the first peak, shoulder, and second peak of the $200 \mathrm{mTorr}$ ion flux in Fig. 3(a) [see diagram, Fig. 3(b)]. This spectral region for absorption was chosen because both 
(b)

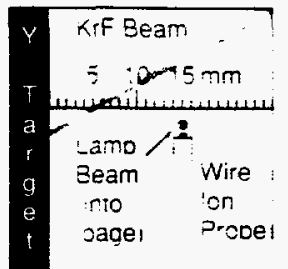

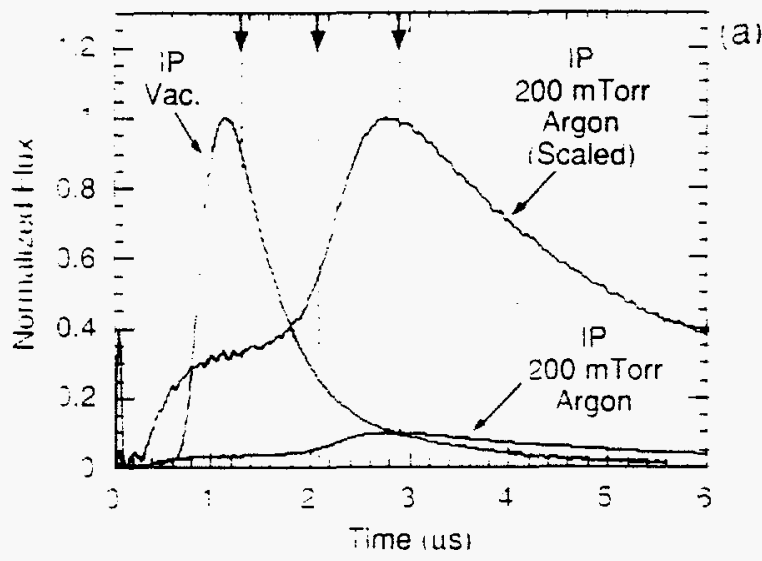

(a)
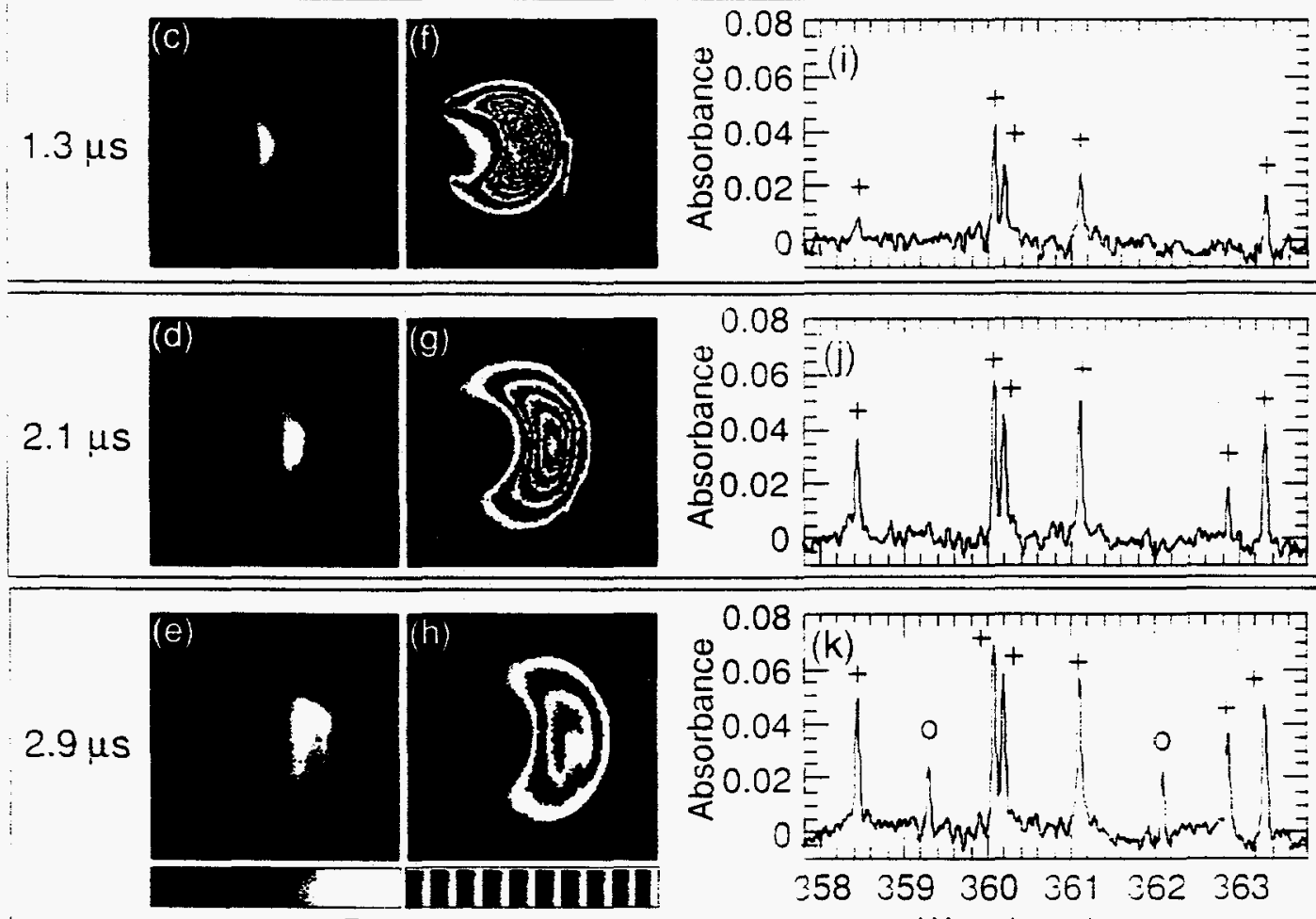

Palettes

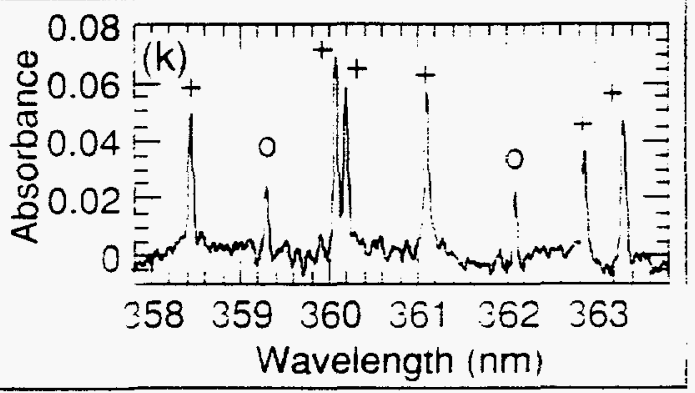

Figure 3: (a) Ion probe current puises measured $\mathrm{d}=1.5 \mathrm{~cm}$ along the normal to an yttrium target following KrFlaser irradiation $\left(0.8 \mathrm{~J} / \mathrm{cm}^{2}\right)$ in vacuum $\left(1 \times 10^{-6}\right.$ Torr $)$ and $200 \mathrm{~m}$ Torr argon. The bimodal $200 \mathrm{~m}$ Torr waveform is piotted in correct magnitude relative to the vacuum pulse and replotted scaled by a factor of 10 . The peak of the vacuum pulse corresponds to a current tlux of $25 \mathrm{~A} / \mathrm{cm}^{2}$. Imaging and optical absorption spectroscopy were performed at the three times indicated in $200 \mathrm{~m}$ Torr argon. (b) Schematic of the side-on view of the $Y$-target and focusing sheet of $\mathrm{KrF}$-irradiation, wire ion probe at $\mathrm{d}=1.5 \mathrm{~cm}$, and position of Xe-lamp beam (propagating into the page) used for optical absorption spectroscopy just above the wire probe tip. (c) Gated ICCD photographs of the total visible optical plasma emission during $50 \mathrm{~ns}$ gates at the indicated time delays following KrF-laser irradiation of yttrium metal into $200 \mathrm{~m}$ Torr argon. The times correspond to the first peak, shoulder, and second peak of the ion probe waveform in (a). The images represent equal exposures: (c)-(e) utilize the grayscale paiette and are independently normalized to $10.000,20,000$, and 38.000 counts, respectively, while (f) - (h) utilize the 10-grayscale palette and are all normalized to 38.000 counts. (i)-(k) Time-resolved optical absorption spectra ( $-2 \mathrm{~cm}$ optical path length, $d=1.5 \mathrm{~cm}, 100$-spectra averaged with $200 \mathrm{~ns}$ gates centered at the imaged times) in $200 \mathrm{mTorr}$ argon show that ground-state $\mathrm{Y}^{+}$ion lines (indicated by + ) dominate absorption at (c) $1.3 \mu s$ and (b) $2.1 \mu$ s (first peak, shoulder of ion probe signal): $358.45,360.07,360.19,361.10,362.87,363.31 \mathrm{~nm}$. Y neutral absorption becomes (indic. by o) noticeable in the second peak of the ion probe signal as indicated in (k) $2.9 \mu \mathrm{s}$, at $359.29,362.09 \mathrm{~nm}$. 

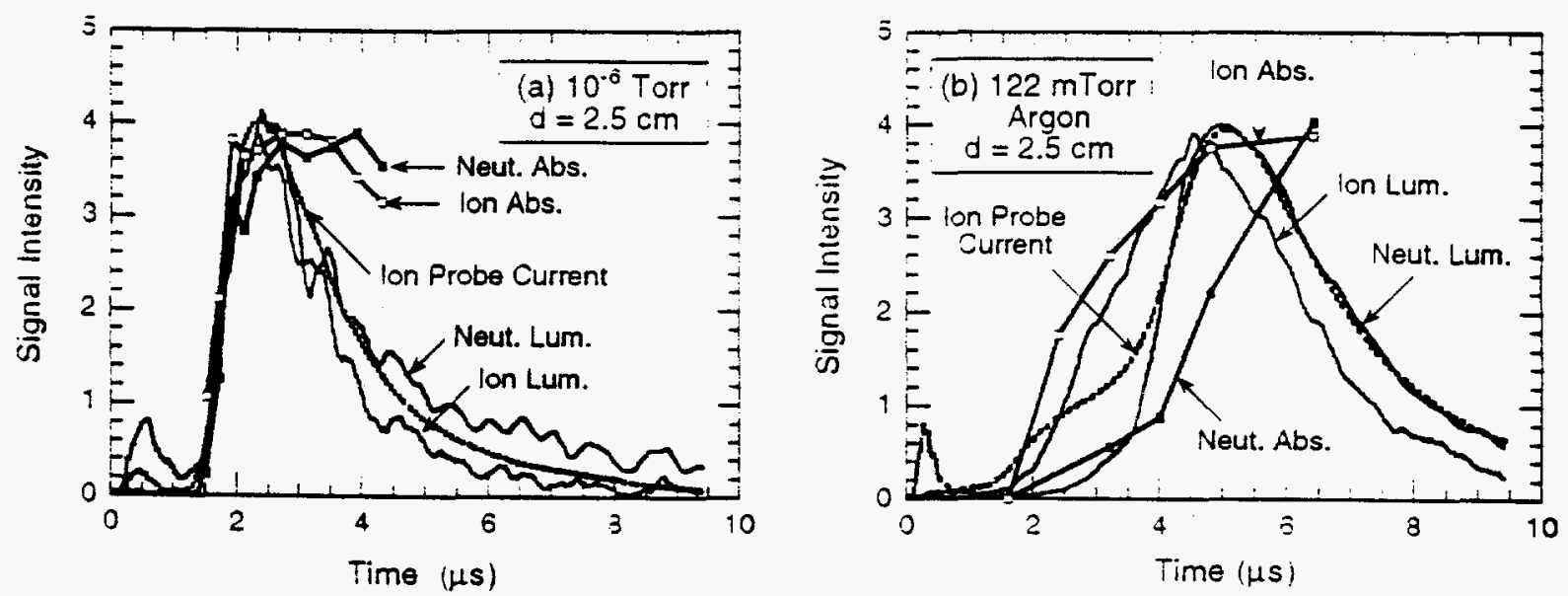

Figure 4: Normalized ion probe current (IP). luminescence (lum.) intensities of $\mathrm{Y}^{*}(410.2 \mathrm{~nm})$ and $\mathrm{Y}^{+^{*}}(363.3 \mathrm{~nm})$, and optical absorbencies (abs.) of $Y(362.1 \mathrm{~mm})$ and $Y^{+}(363.3 \mathrm{~nm})$ at $\mathrm{d}=2.5 \mathrm{~cm}$ following $0.8 \mathrm{~J} / \mathrm{cm}^{2} \mathrm{KrF}$-laser irradiation of yturium in (a) vacuum $\left(1 \times 10^{-6} \mathrm{Torr}\right)$ and (b) $122 \mathrm{mTorr}$ argon. Scaling factors: (a) lum: $\mathrm{Y}^{*}(/ 3)$, $\mathrm{Y}^{+^{*}}(\times 1)$, abs: $Y(\times 70), Y^{+}(\times 94)$, IP $(m V / 81)$, (b) lum: $Y^{*}(/ 23), Y^{+*}(/ 12.5)$, abs: $Y(\times 100), Y^{+}(\times 70)$, IP $(\mathrm{mV} / 81)$.

ground-state neutral $(Y)$ and ground-state ionic $\left(Y^{+}\right)$populations could simultaneously be investigated (ionic lines indicated by + and neutral lines indicated by $o$ ). In addition, quantitative imaging was performed at the same three times and these images are again plotted in two representations (see figure caption) in Fig. 3(c)-3(e) and Fig. 3(f)-3(h).

At $1.3 \mu \mathrm{s}$ [Fig. 3(c) and 3(f)], very weak optical emission is present at the probe position during the first peak of the ion tlux signal. However, the optical absorption spectrum [Fig. 3(i)] reveals strong $\mathrm{Y}^{+}$absorption [lines indicated by + in Figs. 3(a)-3(c)] at this time, confirming the penetration of target ions through the background gas at 'vacuum' velocities. At $2.1 \mu \mathrm{s}$ [Fig. 3(d) and $3(\mathrm{~g})$ ] the steep gradient of plume luminescence has reached the probe at $1.5 \mathrm{~cm}$ (shoulder of the ion probe current. Fig. 3(a)). The peak luminescence is 1.9 times smaller than at $1.3 \mu \mathrm{s}$, and the optical absorption spectrum is still dominated by $\mathrm{Y}^{+}$absorption. During the second peak of the ion probe current at $2.9 \mu \mathrm{s}$. the probe is immersed in the hrightest region of luminescence [Fig. 3(e) and 3(h)] which is half the peak intensity of that at $2.1 \mathrm{\mu s}$. In addition to the ion lines, ground-state neutral vttrium becomes noticeable [lines indicated by 0 in Fig. $3(\mathrm{k})$ ].

At longer distances. a similar situation exists at lower pressures. Figure + shows a comparison of ion probe current, optical emission intensity (of $\mathrm{Y}^{*}$ and $\mathrm{Y}^{+^{*}}$ ), and optical absorbance (of $\mathrm{Y}$ and $\mathrm{Y}^{+}$) time dependencies at $\mathrm{d}=2.5 \mathrm{~cm}$ following $\mathrm{KrF}$-laser irradiation of yttrium in (a) vacuum $11 \times 10^{-6}$ Torr) and (b) $122 \mathrm{mTorr}$ argon. In vacuum [Fig. $4(a)$ ], ground-state neutrals and ions are found (through optical absorption) in coincidence with excited ions and neutrals (from optical emission) on the leading edge of the ion probe current. In background argon [Fig. 4(b)], excited and ground-state $\mathrm{Y}^{+}$ions dominate the tirst peak of the ion probe wavetorm. while excited and ground-state neutrals appear in the delayed, second distribution.

\section{DISCUSSION AND CONCLUSIONS}

In summary, simultaneous application of the four diagnostic techniques confirms that a component of target material is transmitted through low-pressure background gases with little or no delay compared to vacuum. Weak optical emission from this 'fast' component originates principally from yttrium ions. Ground state and excited neutrals, which are present during the 'fast' vacuum distribution, appear delayed (or depopulated) at similar times in background gases and are correlated principally with the bright luminescence at the slowed. second peak of the ion probe signal. 
The data are consistent with scattering over extended distances in wnich ions and atoms in the ablation plume undergo collisions with mean-tree-paths $-1 \mathrm{~cm}$ at $200 \mathrm{~m}$ Torr. Plume material is retarded and lost from the 'tast' vacuum velocity distribution due to collisional momentum transfer with the background gas (as well as other retarded plume material). This slowed material becomes observable as a distinct. second distribution only for a limited range of distances and pressures. Alternate explanations have been proposed, inciuding ion-ion interactions with pre-ionized background gas atoms near the target surface, $11-13$ however the imaging data implies interactions continuing at long distances from the target surface as evidenced by the plume luminescence.

The luminescence represents populations of short-lived excited states (radiative lifetimes $-10 \mathrm{~ns}$ which can be populated by a variety of collisional processes, including three-body recombination of ions with electrons, electron-impact excitation of ground and low-lying states of neutrals and ions, and collisional or radiative deactivation of Rydberg states. The luminescence intensity does not necessarily correspond to the overail plume density, but is determined by velocity- or temperature-dependent rate constants and their effects on the population kinetics of luminescent levels. The enhanced luminescence in the slowed 'shock region' is explained generally by tavorable population kinetics there. The depletion of ground-and excited-state neutrals observed in the 'fast' distribution is more likely the result of conversion to neutral Rydberg states or ions than a preferential slowing of neutrais. A detailed experimental description of the plume luminescence and implications for plume temperatures and density-redistributions, as well as computer simulation of the above effects. will be presented elsewhere.

\section{ACKNOWLEDGMENTS}

The authors gratefully acknowledge many helptul discussions with C.-L. Liu. J. N. Leboeut, K.-R. Chen, J. Donato, R. F. Wood, D. P. Norton. and D. H. Lowndes. This work was supported by the Division of Materials Sciences, U.S. Department of Energy under contract DE-AC05-840R21400) with Martin Marietta Energy Systems, Inc.

\section{REFERENCES}

?. D. B. Geohegan. p. 28 in Laser Ablation: Mechanisms and Applications. ed. hy J. C. Miller and R. F. Haglund. Springer-Veriag, Heidelberg, (1991).

2. D. B. Geohegan. Ch. 5. in Pulsed Laser Deposition of Thin Films. D. B. Chrisey and G. K. Hubler (eds.), Wiley, New York (1994) and references cited therein.

$\therefore$. Roger Kelly and Antonio Miotello. (Ibid).Ch. 3.

4. D. B. Geohegan. Appi. Phys. Letr. 60. 2732 (1992).

5. D.B. Geohegan and A.A. Puretzky, submitted to Appl. Phys. Lett. . (1995).

6. D. B. Geohegan.Thin Solid Films. 220, 138 (1992).

7. D. B. Geohegan, p. 73 in Laser Ablation of Electronic Materials: Basic Mechanisms and Applications, ed. by E. Fogarassy and S. Lazare, North Holland (1992).

8. J. C. S. Kools, J. Appl. Phvs. 74. 6401 (1993).

9. D. B. Geohegan, pp. 165-185 in Excimer Lasers, NATO ASI Series E: Applied Sciences Vol. 265, L. D. Laude (ed.). Kluwer, Netherlands (1994).

10. D. B. Geohegan and D. N. Mashburn, Appl. Phys. Lett. 55, 2345 (1989).

11. R. R. Goforth and David W. Koopman, Phys. Fluids 17, 698 (1974).

12. David W. Koopman and R. R. Goforth, Phys. Fluids 17, 1560 (1974).

13. David W. Koopman. Phys. Fluids. 15, 1959 (1972). 